\title{
Desempenho agronômico de genótipos de soja hortaliça cultivados no recôncavo Baiano
}

\author{
Jamile M. da S. dos Santos ${ }^{1}$, Clovis P. Peixoto ${ }^{1}$, Marco A. S. Rangel ${ }^{2}$, \\ Thyane V. da Cruz ${ }^{3}$, Rose N. A. da Silva ${ }^{1} \&$ Carlos A. da S. Ledo ${ }^{2}$
}

\begin{abstract}
1 Universidade Federal do Recôncavo da Bahia, Centro de Ciências Agrárias, Ambientais e Biológicas, Campus Universitário, Centro, CEP 44380-000, Cruz das Almas-BA, Brasil. E-mail: agromyle@hotmail.com; cppeixot@gmail.com; roseufrb.agro@hotmail.com

${ }^{2}$ Embrapa Mandioca e Fruticultura, Rua Embrapa, s/n, CEP 44380-000, Cruz das Almas-BA, Brasil. Caixa Postal 007. E-mail: marco.rangel@embrapa.br; carlos.ledo@embrapa.br

${ }^{3}$ Instituto Federal de Educação, Ciência e Tecnologia da Bahia, Campus Porto Seguro, Bairro Fontana, CEP: 45.810-000, Porto Seguro- BA, Brasil. E-mail: thyvc@yahoo.com.br
\end{abstract}

\section{RESUMO}

O objetivo deste trabalho foi avaliar os componentes de produção da planta e a produtividade de quatro genótipos de soja hortaliça cultivados no recôncavo Baiano. $O$ experimento foi realizado no campo experimental do Centro de Ciências Agrárias, Ambientais e Biológicas da Universidade Federal do Recôncavo da Bahia. O delineamento experimental foi em blocos casualizados, com sete repetições. Foram avaliados quatro genótipos de soja hortaliça: JLM 17, BR 94, BRS 267 e BRS 258, anos agrícolas de 2010 e 2011. Determinaram-se o número total de vagens e o número total de grãos por planta, a massa de 100 grãos e a produtividade de grãos imaturos $\left(\mathrm{kg} \mathrm{ha}^{-1}\right)$. Os dados foram submetidos à análise de variância conjunta e as médias comparadas pelo teste de Tukey a $5 \%$ de probabilidade. Existe variação nos componentes de produção entre os genótipos testados os quais evidenciam efeito de compensação para os componentes da produção no sentido de uniformizar o rendimento final de grãos. Quanto à produtividade de grãos o BRS 267 se destaca como mais promissor para a Região.

Palavras-chave: Glycine max L. Merril, grãos imaturos, rendimento

\section{Agronomic performance of vegetable soybean genotypes cultivated in the recôncavo Baiano, Brazil}

\begin{abstract}
The objective of present study was to evaluate the components of production and productivity of four vegetable soybean genotypes grown in the recôncavo Baiano. The experiment was carried in the experimental field of the Center of Agricultural, Environmental and Biological Sciences of Federal University of Recôncavo of Bahia. The experimental design consisted of randomised blocks with seven replications. Four vegetable soybean genotypes: JLM 17, BR 94, BRS 267 and BRS 258, were evaluated in crop years 2010 and 2011. The total number of pods and total number of grains per plant, weight of 100 grains and immature grain yield $\left(\mathrm{kg} \mathrm{ha}^{-1}\right)$ were determined. The data were subjected to analysis of variance, and means were compared by Tukey test at $5 \%$ probability. There is variation in yield components between genotypes, which showed compensation effect for production components providing a uniform grain yield at end. The productivity found, highlight the BRS 267 as more promising for the region.
\end{abstract}

Key words: Glycine max L. Merril, immature grains, yield 


\section{Introdução}

O consumo da soja na alimentação humana entre os brasileiros está aumentando em decorrência da divulgação dos seus benefícios à saúde humana, além do crescimento da oferta dos produtos à base de soja, com melhor qualidade (CarrãoPanizzi \& Silva, 2011).

A utilização da soja na alimentação visando explorar as qualidades nutracêuticas é realizada principalmente por meio de grãos verdes, conhecidos como soja verde, soja hortaliça ou edamame (Mendonça \& Carrão-Panizzi, 2003). Os grãos de cultivares de soja hortaliça são caracteristicamente maiores e considerados melhores em sabor, textura e tempo de cozimento (Konovsky \& Lumpkin, 1990).

Devido à sua multiplicidade de aplicações na alimentação humana, vem crescendo a importância do cultivo da soja hortaliça. Baseado nisto, Machado (2010) sugere a necessidade do desenvolvimento de novas tecnologias que permitam a exploração do potencial de cada cultivar para as diferentes regiões de cultivo, visando ao aumento da fronteira agrícola, da produtividade e do fornecimento de um produto alternativo para a população.

O sistema de cultivo para a soja hortaliça é o mesmo da soja tradicional (Mendonça \& Carrão-Panizzi, 2003) e existem várias cultivares desenvolvidas pela Embrapa Soja com a finalidade de colheita para o consumo de grãos verdes (estádio R6, pela escala de Fehr \& Caviness, 1977), que estão sendo avaliadas em diferentes regiões do país, para geração de informações.

A soja hortaliça apresenta outras características especiais, como sementes graúdas com alto teor de proteína, teor reduzido do inibidor de tripsina Kunitz, ausência de enzimas lipoxigenase que conferem sabor adocicado, permitindo o consumo in natura dos grãos (Charlo et al., 2011). Assim, o êxito na produção de soja hortaliça depende da escolha correta da cultivar adaptada às condições ambientais de cada local considerando-se latitude e tipo de solo, além de outros aspectos climáticos (Padovan, 2007). Desta forma, tornamse necessários os ensaios regionalizados englobando novas cultivares de soja hortaliça cultivados em diferentes condições edafoclimáticas, para só assim poder atender às demandas do mercado consumidor.

Para o estudo desses novos genótipos Peixoto et al. (2000) indicam que as características quantitativas, como os componentes de produção de grãos da planta (número de vagens por planta, número de grãos por planta e massa dos grãos) e a produtividade, são mais importantes para a escolha da cultivar superior de soja para cada ambiente.

Diante do exposto, este trabalho propôs avaliar o desempenho dos componentes de produção da planta e a produtividade de genótipos de soja hortaliça cultivados nas condições edafoclimáticas do recôncavo Baiano.

\section{Material e Métodos}

O experimento foi realizado na área experimental do Centro de Ciências Agrárias, Ambientais e Biológicas da Universidade Federal do Recôncavo da Bahia, cidade de Cruz das Almas, cujas coordenadas geográficas são $12^{\circ} 40^{\prime} 19^{\prime \prime}$ Latitude Sul e 39 $06^{\prime}$ '22" Longitude Oeste de Greenwich e altitude de $220 \mathrm{~m}$. O clima é considerado tropical quente e úmido com pluviosidade média anual de $1170 \mathrm{~mm}$ e variações entre 900 e $1300 \mathrm{~mm}$, sendo os meses de março a agosto os mais chuvosos e de setembro a fevereiro, os mais secos. A temperatura média anual é de $24,5^{\circ} \mathrm{C}$ e umidade relativa de $80 \%$ (Rezende, 2004).

O solo do recôncavo Baiano é classificado como Latossolo Amarelo Álico Coeso, de textura franco-argiloso-arenoso e relevo plano, é um solo profundo que apresenta horizontes subsuperficiais coesos (Rezende, 2000) cujas características químicas estão descritas na análise de solo (Tabela 1).

As sementes utilizadas no plantio foram oriundas da Embrapa Soja, sendo avaliadas as linhagens JLM 17 (porte médio, massa seca de 100 sementes $=20 \mathrm{~g}$, flor de coloração roxa e hilo marrom) e BR 94 (porte médio, massa seca de 100 sementes $=30 \mathrm{~g}$, flor de coloração branca e hilo claro) e as cultivares comerciais BRS 267 (porte médio, massa seca de 100 sementes $=27 \mathrm{~g}$, flor de coloração roxa e hilo claro) e BRS 258 (porte médio, massa seca de 100 sementes= $25 \mathrm{~g}$, flor de coloração branca e hilo claro). O delineamento experimental adotado foi o de blocos casualizados com sete repetições considerando-se o desempenho dos genótipos nos anos agrícolas 2010 e 2011. Todos os tratos culturais, desde o preparo de solo até a época da colheita, foram realizados com base nas recomendações para a cultura (Embrapa Soja, 2011).

A parcela experimental (Figura 1) foi constituída de oito linhas de 5,0 $\mathrm{m}$ de comprimento, espaçadas $0,5 \mathrm{~m}$ nas entrelinhas

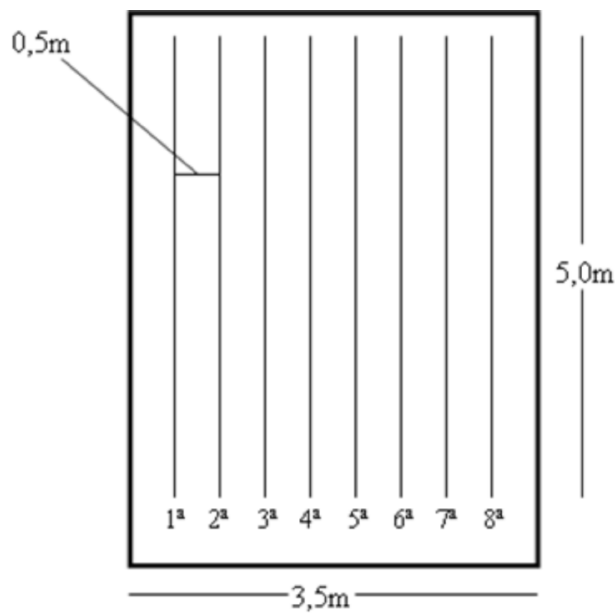

Figura 1. Esquema da parcela experimental. Bordaduras: $1^{\mathrm{a}}, 4^{\mathrm{a}}$ e $8^{\mathrm{a}}$. Linhas úteis para a coleta de dados: $2^{\mathrm{a}}$ e $3^{\mathrm{a}}$ para amostras destrutivas e $5^{\mathrm{a}}, 6^{\mathrm{a}}$ e $7^{\mathrm{a}}$ para produtividade

Tabela 1. Análise química do solo do experimento nos dois anos de cultivo, na profundidade de $0-20 \mathrm{~cm}$

\begin{tabular}{|c|c|c|c|c|c|c|c|c|c|}
\hline \multirow{2}{*}{$\begin{array}{c}\mathrm{pH} \\
\left(\mathrm{CaCl}_{2}\right)\end{array}$} & $\mathbf{P}$ & $\mathbf{K}$ & $\mathbf{C a}$ & Mg & $\mathrm{Ca}+\mathrm{Mg}$ & $\mathbf{A l}$ & $\mathbf{H}+\mathbf{A l}$ & CTC & \multirow{2}{*}{$\begin{array}{l}V \\
\%\end{array}$} \\
\hline & \multicolumn{2}{|c|}{$\mathrm{mg} \mathrm{dm}^{3}$} & \multicolumn{6}{|c|}{$\mathrm{cmol}_{\mathrm{c}} \mathrm{dm}^{-3}$} & \\
\hline \multicolumn{10}{|c|}{ Ano 2010} \\
\hline 4,75 & 1 & 30 & 1,0 & 0,9 & 1,9 & 0,3 & 2,89 & 4,92 & 41,26 \\
\hline \multicolumn{10}{|c|}{ Ano 2011} \\
\hline 5,3 & 26 & 0,16 & 1,0 & 0,6 & 1,6 & 0,2 & 2,96 & 5,74 & 31 \\
\hline
\end{tabular}


e com densidade de 12 plantas $\mathrm{m}^{-1}$ linear. Das oito linhas duas $\left(2^{\mathrm{a}}\right.$ e $\left.3^{\mathrm{a}}\right)$ foram utilizadas para análise de crescimento (amostras destrutivas de plantas) e três $\left(5^{\mathrm{a}}, 6^{\mathrm{a}}\right.$ e $\left.7^{\mathrm{a}}\right)$ para determinação da produtividade de grãos, representando a parcela útil. As duas linhas externas $\left(1^{\mathrm{a}} \mathrm{e} 8^{\mathrm{a}}\right)$ e uma das centrais $\left(4^{\mathrm{a}}\right)$ foram consideradas bordaduras. Para determinação dos componentes de produção da planta e da produtividade as plantas foram colhidas quando se encontravam em estádio reprodutivo R6 (Fehr \& Caviness, 1977) com vagens desenvolvidas e $100 \%$ de granação.

A determinação dos componentes de produção da planta, número total de vagens e de grãos, foi obtida pela contagem direta por planta, em amostragens de 10 plantas na parcela útil.

A produtividade foi determinada a partir da colheita manual de todas as plantas da área útil de cada parcela e após a retirada das vagens os grãos foram debulhados, limpos e acondicionados em sacos plásticos, para posterior pesagem, obtendo-se o rendimento de grãos imaturos em $\mathrm{kg}_{\text {parcela }}{ }^{-1}$, os quais foram estimados posteriormente em $\mathrm{kg} \mathrm{ha}^{-1}$. Simultaneamente e para determinação da massa de 100 grãos frescos foram separadas oito subamostras de 100 grãos por parcela, cujas massas foram determinadas em balança com sensibilidade de centésimos de grama, sendo tais procedimentos adaptados segundo prescrições estabelecidas pelas Regras de Análise de Sementes (Brasil, 2009).

Com vista à determinação da umidade dos grãos utilizouse o método da estufa a $105{ }^{\circ} \mathrm{C}$ por 24 onde esses grãos foram corrigidos, posteriormente, para $13 \%$ de acordo com a fórmula: $\mathrm{Mc}=\mathrm{Mo}$ [1 - (Uo / 100)] / [1-(Uc / 100)], em que: Mc é a massa corrigida; Mo é a massa obtida; Uo é o grau de umidade observado em porcentagem e Uc é o grau de umidade de correção em porcentagem (Brasil, 2009).

Os dados obtidos foram submetidos à análise de variância e as médias comparadas pelo teste de Tukey, a $5 \%$ de probabilidade.

\section{Resultados e Discussão}

As características climáticas durante o período de experimentação se encontram dispostas na Figura 2. Como se observa, o fotoperíodo e a umidade relativa são praticamente constantes; ao mesmo tempo, a temperatura média do ar apresentou variação reduzida ao longo dos dois períodos avaliados; entretanto, a precipitação foi variável, e os maiores índices ocorreram no mês de julho de 2010 e em junho de 2011. As chuvas influenciam na formação das flores, de vagens e no enchimento de grãos na cultura da soja; em situação de restrição hídrica há um aumento na percentagem de abortos florais e menor formação de vagens.

A restrição hídrica no período de enchimento de grãos irá refletir, sem dúvida, no rendimento final, haja vista que os grãos ficam menores e com menor teor de umidade ou podem ser constatadas muitas vagens chochas na planta. A disponibilidade hídrica, portanto, torna-se necessária, sobretudo para a soja hortaliça uma vez que os grãos são colhidos ainda verdes, com alto teor de umidade.

É importante salientar que não se pode inferir que houve influência negativa do ambiente nas variáveis estudadas mas apenas ressaltar que as condições climáticas, principalmente a

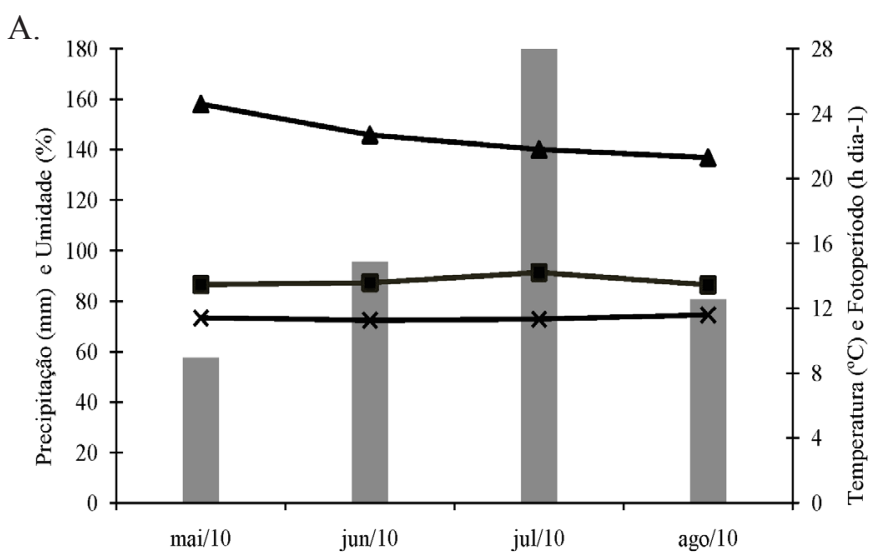

B.

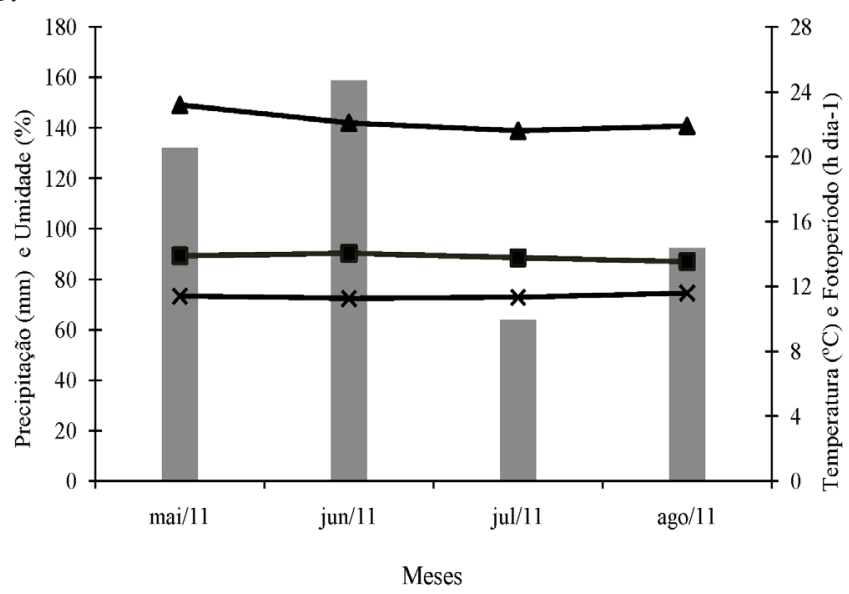

Figura 2. Valores médios mensais de precipitação total $(\mathrm{mm})$, umidade relativa do ar (\%), fotoperíodo ( $\mathrm{h} \mathrm{dia}^{-1}$ ) e temperatura do ar $\left({ }^{\circ} \mathrm{C}\right)$ durante os meses de maio a agosto nos anos de 2010 (A) e 2011 (B), no município de Cruz das Almas - BA

precipitação no ano de 2010 (Figura 2A), foram mais favoráveis ao desenvolvimento da soja hortaliça que no ano de 2011 (Figura 2B), com quase nenhum prejuízo aos componentes da produção da planta, refletindo em uma pequena redução na produtividade, neste último ano.

Os genótipos avaliados apresentaram diferenças significativas para todas as características estudadas (Tabela 2) já para o fator ano, nem todas as características foram influenciadas em razão da pouca variação dos fatores climáticos, nos dois anos de estudo.

Para a característica número de vagens por planta (Tabela 3) em 2010, os genótipos JLM 17 (26,56), BR $94(25,21)$

Tabela 2. Resumo da análise de variância conjunta para as variáveis número de vagens (NV), número de grãos (NG), massa de 100 grãos (M100) e produtividade (PROD) de quatro genótipos de soja hortaliça (JLM 17, BR 94, BRS 267 E BRS 258), em dois anos de cultivo no recôncavo Baiano

\begin{tabular}{lccccc}
\hline \multirow{2}{*}{ FV } & \multirow{2}{*}{ GL } & \multicolumn{4}{c}{ QM } \\
\cline { 3 - 6 } & & NV & NG & M100 & PROD \\
\hline Bloco/Ano & 12 & $63,08^{*}$ & 280,84 & 4,26 & $1460218,31^{* *}$ \\
Ano & 1 & $64,50^{*}$ & 242,23 & 2,05 & $18258602,35^{* *}$ \\
Genótipo & 3 & $134,35^{* *}$ & $410,80^{*}$ & $487,14^{* *}$ & $28735950,44^{* *}$ \\
Ano x Genótipo & 3 & $62,19^{* *}$ & $535,15^{*}$ & 2,30 & $3515466,25^{* *}$ \\
Erro & 36 & 14,87 & 150,34 & 4,99 & $494000,053^{* *}$ \\
\hline Média Geral & & 24,39 & 49,22 & 50,20 & 5003,48 \\
CV (\%) & & 15,81 & 24,91 & 4,45 & 14,05 \\
\hline
\end{tabular}

* Significativo a $5 \%$ e ** Significativo a $1 \%$ de probabilidade pelo teste $\mathrm{F}$ 
e BRS $258(23,61)$ apresentaram, número de vagens por planta superior ao apresentado pelo BRS 267 (17,69); em 2011 os genótipos JLM $17(27,53)$ e BR 94 (28,96) também apresentaram os maiores valores em relação ao genótipo BRS 258 .

Tabela 3. Valores médios de número de vagens por planta (NV) de quatro genótipos de soja hortaliça, em dois anos de cultivo no recôncavo Baiano

\begin{tabular}{ccc}
\hline Genótipo & \multicolumn{3}{c}{ Ano } \\
\cline { 2 - 3 } & $\mathbf{2 0 1 0}$ & $\mathbf{2 0 1 1}$ \\
\hline JLM 17 & $26,56 \mathrm{aA}$ & $27,53 \mathrm{aA}$ \\
BR 94 & $25,21 \mathrm{aA}$ & $28,96 \mathrm{aA}$ \\
BRS 267 & $17,90 \mathrm{bB}$ & $24,80 \mathrm{abA}$ \\
BRS 258 & $23,61 \mathrm{aA}$ & $20,59 \mathrm{bA}$ \\
\hline CV (\%) & \multicolumn{3}{c}{15,81} \\
\hline
\end{tabular}

Médias seguidas pela mesma letra minúscula na coluna e maiúscula na linha não diferem entre s pelo teste de Tukey, a $5 \%$ de probabilidade

Entre esses anos, a diferença significativa ocorreu apenas no genótipo BRS 267 que apresentou, no ano de $2010(17,90)$ menor número de vagens por planta que em $2011(24,80)$, com um aumento de $38 \%$ devendo-se, provavelmente, ao desempenho do genótipo.

Segundo Peixoto et al. (2000), apenas o número de vagens não é um componente que garanta a produtividade das plantas, pois a mesma não depende apenas de um componente de produção da planta tendo que haver um ajuste entre os mesmos. Caso a produção, de vagens de determinado genótipo apresente valores reduzidos, não é recomendável descartar o genótipo, pois existe o efeito compensatório do número de grãos e do seu peso, o que é ideal para a soja hortaliça, ou seja, plantas com número reduzido de vagens e com grãos maiores e mais pesados.

Mesmo sendo preferível para a soja hortaliça obter-se menor quantidade de vagens com grãos de maior massa, os números de vagens observados neste trabalho estão abaixo dos valores relatados por Viana et al. (2009), trabalhando com três genótipos de soja hortaliça em Areia - PB (25 a 42 vagens), Smiderle et al. (2007), que avaliaram a produtividade e a qualidade de sementes de oito genótipos de soja hortaliça no cerrado de Roraima (23 a 63 vagens) e em relação aos resultados de Castoldi et al.(2011), que trabalharam com seis genótipos de soja hortaliça em Jaboticabal - SP (48 a 75 vagens).

Pode-se atribuir esses baixos valores no número de vagens por planta observados, ao fato dos genótipos testados terem evidenciado crescimento reduzido, com menor altura de plantas detectada visivelmente no campo. Por conseguinte, é provável que isto resultou em menores números de flores na planta e, por consequência, um número menor de nós, o que deve ter proporcionado menores pontos de inserção de vagens. Valores próximos de NV foram observados por Machado (2010), variando de 17,8 a 29,2 vagens por planta, trabalhando com soja hortaliça em duas épocas de semeadura no recôncavo sul Baiano.

O porte mais reduzido das plantas pode influenciar no menor número de vagens devido a alguma compensação da planta; entretanto, essa compensação estaria mais relacionada à área foliar disponível, ao estado nutricional e à disponibilidade hídrica, que poderiam refletir no número de nós e "pegamento" das flores (Embrapa Soja, 2011).
Neste trabalho no número de genótipos escolhidos tomouse por base a disponibilidade de sementes e sua capacidade de adaptação, quando introduzidos em outras regiões tradicionais no cultivo, uma vez que no Recôncavo Baiano ainda são escassos os trabalhos com a cultura e não há um programa de melhoramento direcionado a essas condições ambientais.

Com relação ao número de grãos (Tabela 4), no ano de 2010 os genótipos não diferiram estatisticamente apresentando valores entre 43 e 49 grãos por planta; já em 2011 os genótipos BR 94 e BRS 267, se mostraram superiores apresentando os maiores números de grãos por planta ( 67 e 51 , respectivamente), equivalendo a cerca de 41 e $35 \%$ de superioridade em relação ao genótipo BRS 258, de menor desempenho. Machado (2010) avaliou alguns genótipos de soja hortaliça e verificou que o número total de grãos por planta variou de 29 a 50 grãos, valores esses, inferiores aos encontrados neste trabalho, quando foram constatados de 40 a 67 grãos por planta.

Tabela 4. Valores médios de número de grãos por planta (NG) de quatro genótipos de soja hortaliça, em dois anos de cultivo no recôncavo Baiano

\begin{tabular}{ccc}
\hline \multirow{2}{*}{ Genótipo } & \multicolumn{3}{c}{ Ano } \\
\cline { 2 - 4 } & $\mathbf{2 0 1 0}$ & $\mathbf{2 0 1 1}$ \\
\hline JLM 17 & $49,25 \mathrm{aA}$ & $46,94 \mathrm{bA}$ \\
BR 94 & $47,06 \mathrm{aA}$ & $67,07 \mathrm{aA}$ \\
BRS 267 & $43,39 \mathrm{aA}$ & $50,64 \mathrm{abA}$ \\
BRS 258 & $48,87 \mathrm{aA}$ & $40,54 \mathrm{bA}$ \\
\hline CV $(\%)$ & \multicolumn{3}{c}{24,91} \\
\hline
\end{tabular}

Médias seguidas pela mesma letra minúscula na coluna e maiúscula na linha, não diferem entre $s i$ pelo teste de Tukey, a $5 \%$ de probabilidade

Cruz (2011) ressalta que o número total de grãos é uma característica de cultivares de soja estreitamente relacionada com o número total de vagens ocorrendo, aí, uma inter-relação entre essas duas características, influenciada pelas condições climáticas e pela capacidade genotípica do material vegetal.

Para a característica massa de 100 grãos (Tabela 5), os genótipos de soja não diferiram estatisticamente entre os anos de cultivo; no entanto, dentro de cada ano os genótipos BR 94, BRS 267 e BRS 258 diferiram estatisticamente do JLM 17 , evidenciamento maior massa de grãos frescos. Segundo Charlo et al. (2008), essa maior massa dos grãos caracteriza um fator desejável em genótipos de soja hortaliça, por ser uma característica que indica materiais com maiores produções de grãos verdes.

Os valores da massa de 100 grãos obtidos neste trabalho (43 a 55 g no primeiro ano e de 42 a 56 g no segundo ano) foram semelhantes aos valores encontrados por Machado (2010) desenvolvendo seu trabalho na região do recôncavo baiano (28 a $52 \mathrm{~g}$ ), aos resultados obtidos por Smiderle et al.

Tabela 5. Valores médios de massa de 100 grãos (M100) em gramas de quatro genótipos de soja hortaliça, em dois anos de cultivo no recôncavo Baiano

\begin{tabular}{ccc}
\hline Genótipo & \multicolumn{3}{c}{ Ano } \\
\cline { 2 - 3 } & $\mathbf{2 0 1 0}$ & $\mathbf{2 0 1 1}$ \\
\hline JLM 17 & $43,29 \mathrm{bA}$ & $42,77 \mathrm{bA}$ \\
BR 94 & $55,49 \mathrm{aA}$ & $56,29 \mathrm{aA}$ \\
BRS 267 & $54,51 \mathrm{aA}$ & $53,64 \mathrm{aA}$ \\
BRS 258 & $48,31 \mathrm{aA}$ & $47,37 \mathrm{aA}$ \\
\hline CV $(\%)$ & & 4,45 \\
\hline
\end{tabular}

Médias seguidas da mesma letra minúscula na coluna e maiúscula na linha, não diferem entre si pelo teste de Tukey, a $5 \%$ de probabilidade 
(2011) em Roraima (40 a 95 g) e a Castoldi et al. (2011), que conduziram as avaliações no estado de São Paulo (46 a 92 g). Essa característica diferencia os materiais estudados e sua interação com o ambiente porém pelo menos nas condições deste estudo foi pouco influenciada pelo ambiente.

Para a característica número total de grãos observou-se tendência de superioridade dos genótipos BRS 267 e BR 94 com o cultivo, no ano de 2011, em relação a 2010; além disto, o genótipo BR 94, que apresentou maior variação para este caráter, foi o que evidenciou maior massa de 100 grãos.

Na Tabela 6 se apresenta o desempenho médio em relação à produtividade de grãos imaturos e produtividade com correção da umidade $\left(\mathrm{kg} \mathrm{ha}^{-1}\right)$ evidenciada pelos quatro genótipos de soja hortaliça, nos anos de 2010 e 2011.

Tabela 6. Valores médios da produtividade grãos imaturos (PROD) e produtividade corrigida para 13\% (PROD C) de quatro genótipos de soja hortaliça, em dois anos de cultivo, no recôncavo Baiano

\begin{tabular}{|c|c|c|}
\hline \multirow{2}{*}{ Genótipo } & \multicolumn{2}{|c|}{ Ano } \\
\hline & 2010 & 2011 \\
\hline & \multicolumn{2}{|c|}{ PROD (kg ha-1) } \\
\hline JLM 17 & $3475,36 \mathrm{bA}$ & $3316,22 \mathrm{bA}$ \\
\hline BR 94 & 6152,36 aA & $4058,73 \mathrm{bB}$ \\
\hline BRS 267 & $6603,42 \mathrm{aA}$ & $5494,45 \mathrm{aB}$ \\
\hline BRS 258 & $6648,32 \mathrm{aA}$ & $4285,72 \mathrm{bB}$ \\
\hline \multirow[t]{2}{*}{ CV (\%) } & \multicolumn{2}{|c|}{14,05} \\
\hline & \multicolumn{2}{|c|}{ PROD C (kg ha-1) } \\
\hline JLM 17 & $1324,32 \mathrm{bA}$ & $1261,40 \mathrm{bA}$ \\
\hline BR 94 & $2134,06 \mathrm{aA}$ & $1407.55 \mathrm{bB}$ \\
\hline BRS 267 & $2478,96 \mathrm{aA}$ & $2062,65 \mathrm{aB}$ \\
\hline BRS 258 & $2410,40 \mathrm{aA}$ & $1553,70 \mathrm{bB}$ \\
\hline CV $(\%)$ & \multicolumn{2}{|c|}{14,18} \\
\hline
\end{tabular}

Médias seguidas da mesma letra minúscula na coluna e maiúscula na linha, não diferem entre si pelo teste de Tukey a $5 \%$ de probabilidade

Observando a produtividade nos dois anos de cultivo (Tabela 6), constata-se que ela não foi maior no ano em que os componentes foram maiores, evento explicado por uma possível diferença de umidade a qual pode ser encontrada nos diferentes genótipos, de acordo com o ano, já que a produtividade da soja hortaliça é medida com grãos imaturos.

Pode-se observar, então, que a produtividade de grãos não é explicada apenas por um dos componentes de produção da planta mas, sim, pelo conjunto do NV, NG e M100, que se ajustam entre si, refletindo em maior ou menor produtividade.

A produtividade média de grãos verdes entre os quatro genótipos avaliados apresentou variação entre $3.475,36 \mathrm{~kg} \mathrm{ha}^{-1}$ (JLM17) e 6.648,32 $\mathrm{kg} \mathrm{ha}^{-1}$ (BRS 258) no ano de 2010, e no ano de 2011 a variação foi de $3.316,22 \mathrm{~kg} \mathrm{ha}^{-1}$ (JLM 17) a 5.494,45 $\mathrm{kg} \mathrm{ha}^{-1}$ (BRS 267) (Tabela 6). Esses valores são similares aos índices de produtividade de grãos imaturos encontrada por Smiderle et al. (2007), que obtiveram valores de produtividade variando de $3.447,00$ a $5.333,00 \mathrm{~kg} \mathrm{ha}^{-1}$, trabalhando com outros genótipos de soja hortaliça.

Os dados de produtividade no primeiro ano de cultivo foram superiores aos do segundo; neste, os genótipos avaliados apresentaram produtividade próxima à encontrada por Machado (2010), (2071,70 a 5854,5 $\left.\mathrm{kg} \mathrm{ha}^{-1}\right)$ estudando diversos genótipos da soja hortaliça nas mesmas condições, no recôncavo Baiano.
As diferenças na produtividade observadas entre os dois anos de cultivo se devem, provavelmente, à distribuição pluviométrica mais uniforme no ano de 2010, coincidindo com as maiores necessidades da cultura da soja, notadamente na fase de enchimento de grãos (Embrapa Soja, 2011), quando a demanda hídrica se torna extremamente importante na translocação dos produtos da fotossíntese (Figura 2).

Visando estabelecer um paralelo com a produtividade da soja tradicional, foi feita a correção da umidade dos grãos da soja hortaliça para $13 \%$, obtendo-se valores que variaram entre 1200 a $2000 \mathrm{~kg} \mathrm{ha}^{-1}$. Embora tais valores estejam abaixo dos comumente encontrados para a soja comercializada, eles estão próximos dos encontrados por Santos et al. (2003) com a soja tradicional em duas épocas de semeadura no recôncavo Baiano (994 a 1945,8 $\mathrm{kg} \mathrm{ha}^{-1}$ )e os relatados por Cruz (2011), em épocas de semeadura tardias no Oeste baiano (980,57 a $2208,98 \mathrm{~kg} \mathrm{ha}^{-1}$ )

\section{Conclusões}

Os componentes da produção da planta de soja hortaliça apresentam variações entre eles, nos anos de cultivo.

Com base na produtividade de grãos imaturos a cultivar BRS 267 demonstrou ser o mais promissor para o cultivo nas condições do recôncavo Baiano.

\section{Agradecimentos}

À Coordenação de Aperfeiçoamento de Pessoal de Nível Superior (Capes), pela bolsa de estudos.

\section{Literatura Citada}

Brasil. Ministério da Agricultura. Regras para análise de sementes. Brasília: LANARV/SNDA, 2009. 365p.

Carrão-Panizzi, M. C.; Silva, J. B. da. Soja na alimentação humana: qualidade na produção de grãos com valor agregado. In: Congresso da soja no Mercusul, 2011, Rosario. Anais..., Rosario: ACSOJA, 2011. <http:// www.mercosoja2011.com.ar/site/wp-content/imagenes/ CARRAO-PANIZZI-Mercedes2.pdf>. 03 Fev. 2013.

Castoldi, R.; Charlo, H. C. O.; Vargas, P. F.; Braz, L. T.; Carrão-Panizzi, M. C. Agronomic characteristics, isoflavone content and Kunitz trypsininhibitor of vegetable soybean genotypes. Horticultura Brasileira v.29, n.2, p.222-227, 2011. <http://dx.doi.org/10.1590/S010205362011000200015>.

Charlo, H. C. O.; Castoldi, R.; Vargas, P. F.; Braz, L. T.; Mendonça, J. L. Desempenho de genótipos de sojahortaliça de ciclo precoce [Glycine max (L.) Merril] em diferentes densidades. Ciência e Agrotecnologia, v.32, n.2, p.630-634, 2008. <http://dx.doi.org/10.1590/S1413$70542008000200044>$.

Charlo, H. C. O; Pessoa, R.; Funichello, M.; Castoldi, R.; Braz, L. T. Desempenho agronômico de dez linhagens de sojahortaliça. Horticultura Brasileira v.29, n.3, p.349-353, 2011. $<$ http://dx.doi.org/10.1590/S0102-05362011000300015>. 
Cruz, T. V. Crescimento e produtividade de soja em diferentes épocas de semeadura com e sem controle químico da ferrugem asiática no Oeste da Bahia. Cruz das Almas: Universidade Federal do Recôncavo da Bahia, 2011. 161p. Tese Doutorado.

Embrapa Soja. Tecnologias de produção de soja - região central do Brasil 2012 e 2013. Londrina: Embrapa Soja; Embrapa Cerrados; Embrapa Agropecuária Oeste, 2011. $262 p$.

Fehr, W. R.; Caviness, C. E. Stages of soybean development. Ames: lowa State University of Science and Techonology, 1977. 11p.

Konovsky, J.; Lumpkin, T. A. Edamame production and use: a global perspective. In: International Conference Soybean Processing and Utilization, 4., 1990, Gongzhuling. Program and abstracts... Gonghuling: Jilin Academy of Agricultural Science, 1990.

Machado, G. da S. Características agronômicas e produtivas de soja hortaliça em diferentes épocas de semeadura no Recôncavo Sul Baiano. Cruz das Almas: Universidade Federal do Recôncavo da Bahia, 2010. 79p. Dissertação Mestrado.

Mendonça, J. L.; Carrão-Panizzi, M. C. Soja-verde: uma nova opção de consumo. Brasília: DF: Embrapa Hortaliças, 2003. 8p. (Comunicado técnico).

Padovan, M. P. Desempenho de cultivares de soja para fins de produção em uma área sob transição a manejo orgânico no Estado de Mato Grosso do Sul. Ensaios e Ciências, v.11, n.2, p.23-32, 2007. <http://sare.anhanguera.com/index. php/rensc/article/view/721/549>. 18 Jan. 2012.
Peixoto, C. P.; Câmara, G. M. de S.; Martins, M. C.; Marchiori, L. F. S.; Guerzoni, R. A.; Mattiazzi, P. Épocas de semeadura e densidade de plantas de soja: I. Componentes da produção e rendimento de grãos. ScientiaAgricola, v.57,n.1,p.89-95, 2000. $<$ http://dx.doi.org/10.1590/S0103-90162000000100015>.

Rezende, J. de O. Recôncavo Baiano, berço da Universidade Federal segunda da Bahia: passado, presente e futuro. Salvador: P\&A, 2004. 194p.

Rezende, J. de O. Solos coesos de tabuleiros costeiros: limitações agrícolas e manejo. Salvador: SEAGRI-SPA, 2000.117p. (Série estudos agrícolas).

Santos, J. M. B.; Peixoto, C. P.; Santos, J. M. B.; Brandelero, E. M.; Peixoto, M. F. S. P.; Silva, V. Desempenho vegetativo e produtivo de cultivares de soja em duas épocas de semeadura no Recôncavo Baiano. Magistra. v.15, n.2, p.111-121, 2003.

Smiderle, O. J. Soja verde para alimentação humana - alternativa para agricultura familiar. <http://www.infobibos.com/ Artigos/2007_2/SojaVerde/index.htm>. 3 Dez. 2011.

Smiderle, O. J.; Gianluppi, V.; Silva, S. R. G.; Silva, J. B. Produtividade e qualidade de sementes de genótipos de soja-hortaliça em cerrado de Roraima 2006/2007. In: Reunião de Pesquisa de Soja da Região Central do Brasil, 24., 2007, Londrina. Anais... Londrina: Embrapa Soja, 2007. p. 159-161.

Viana, J. S.; Bruno, R. L. A.; Mendonça, J. L.; Gonçalves, E. P.; Alves, E. U.; Braga Júnior, J. M. Precocidade de cultivares de soja em sistemas de cultivo com milho em Areia, Estado da Paraíba. Acta Scientiarum. Agronomy, v.31， n.3, p.481-488, 2009. <http://dx.doi.org/10.4025/ actasciagron.v31i3.675>. 